\title{
Synthesis of the Novel 3-Benzotriazole-5-yl difluoromethyl-5-trifluoromethyl benzotriazole Nucleosides
}

\author{
Laila M. Break \\ Correspondence: Laila M. Break, Taif University, Al-Haweiah, P.O.Box 888 Zip Code 21974. Taif, Saudi Arabia \\ Tel: 966-568480801. E-mail: lailabreak@ hotmail.com
}

Received: July 22, 2015 Accepted: August 6, 2015 Online Published: September 9, 2015

doi:10.5539/ijc.v7n2p99

URL: http://dx.doi.org/10.5539/ijc.v7n2p99

\begin{abstract}
Triazole ring is a quite important five-membered heterocycle with three nitrogen atoms, possesses aromaticity and is an electron rich system. Triazole derivatives have been frequently becoming clinical drugs or candidates for the treatment of various types of diseases. Synthesis of the novel of 3-Benztriazole-5-yl difluoromethyl-5-trifluoromethyl benztriazole compound (3). Synthesis and chara-cterization of two new benzotriazole nucleosides with good yields by silyation method.
\end{abstract}

Keywords: 1-O-Acetyl-2,3,5-trihydroxy- $\beta$-D-ribofuranose, Nucleosides, Trifluoromethyl. Reduction,

3-Benzotriazole-5-yl difluoromethyl-5-trifluoromethyl benztriazole

\section{Introduction}

More and more triazole derivatives, with strong pharmacological activity, low toxicity, less adverse effects, fewer multi-drug resistances, high bioavailability, good pharmacokinetics property and drug-targeting, diversity of drug administration, broad spectrum, better curative effect etc., A large number of triazole compounds as clinical drugs or candidates have been frequently employed for the treatment of various types of diseases, Triazole compounds as medicinal drugs, including antifungal, anticancer, antibacterial, antitubercular, antiviral, anti-inflammatory and analgesic,anticonvulsant, antiparasitic, antidiabetic, anti-obesitic, antihista-minic, anti-neuropathic, antihypertensive as well as other biological activities (Zhou \& Wang, 2012 and Khabnadideh et al, 2012). In fact several benzotriazoles have shown potential biological activities such as antimycobacterial (Sanna et al, 2002), antitumor (Handratta et al, 2005) and anti-inflammatory (Dawood et al, 2006) activities.

In recent years, the use of antifungal drugs in human medicine has increased, especially with the advent of AIDS epidemic. Efforts have focused on the development of new, less toxic and more efficacious antifungal drugs with novel mechanism of action (Khabnadideh et al, 2012). Biological activities of ribavirin and homo-N-nucleosides, a novel 1,2,4-triazole nucleoside drug derivative as a potential antiviral agent and anticancer activities (Chun et al, 2005; Xia et al, 2010; Konstantinova et al, 2013; Mosselhi \& Neidlein, 2009 and Kristinsson et al, 1994).

The purpose of this study was to synthesize of some new nucleoside benzotriazole and study their charactrazition.

\section{Material and Methods}

All chemicals were supplied by Sigma-Aldrich and Merck (Germany). IR spectra were recorded for KBr discs on Fourier Transform infrared and Pye Unicam SP 300 Infrared Spectrophotometers at Taif University. 1H NMR spectra were obtained on a Varian (850 MHz) EM 390 USA instrument at King Abdel-Aziz University by using TMS as internal reference. 13C NMR spectra were recorded on a JNM-LA spectrometer $(850 \mathrm{MHz})$ at King Abdel-Aziz University, Saudi Arabia. Elemental analyses were obtained on an Elementar Vario EL 1150C analyzer. Mass spectra were recorded on a JEOL-JMS-AX500 at King Abdel-Aziz University, Saudi Arabia. Purity of the compounds was checked by thin layer chromatography (TLC). Thin layer chroma-tegraphy (TLC) was performed on silica gel sheets F1550 LS 254 of Schleicher \& Schull and column chromatography on Merck silica gel 60 (particle size 0.063-0.20. Melting points were measured on Gallenkamp melting point apparatus (UK) and are uncorrected. The starting materials 4-Amino-3-nitrobenzotrifluoride (1) was prep-ared Pubchem CID: 67865 . 


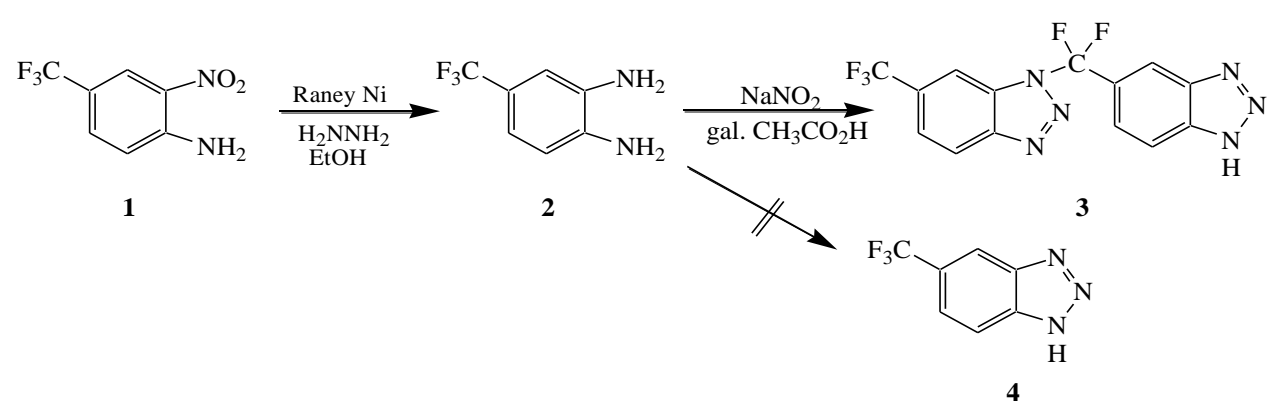

Scheme (1): Synthesis of 3-Benzotriazole-5-(yl)- difluoromethyl-5-trifluoromethyl benzotriazole<smiles>FC(F)(F)c1ccc2nnn(C(F)(F)F)c2c1</smiles>

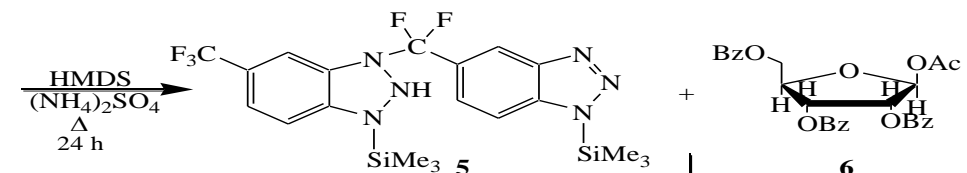

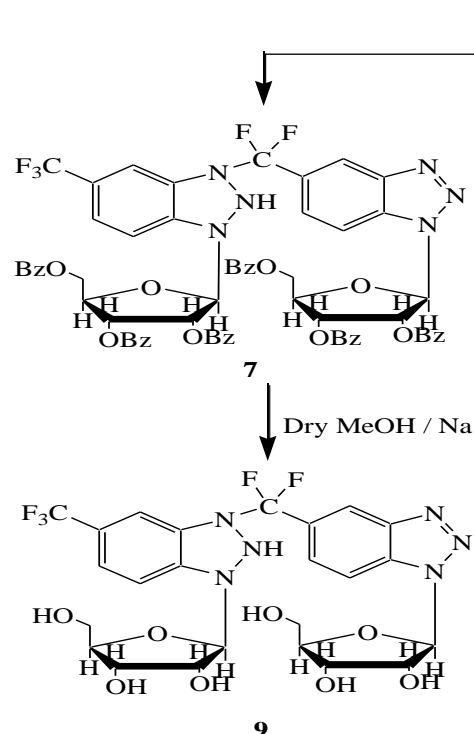

6
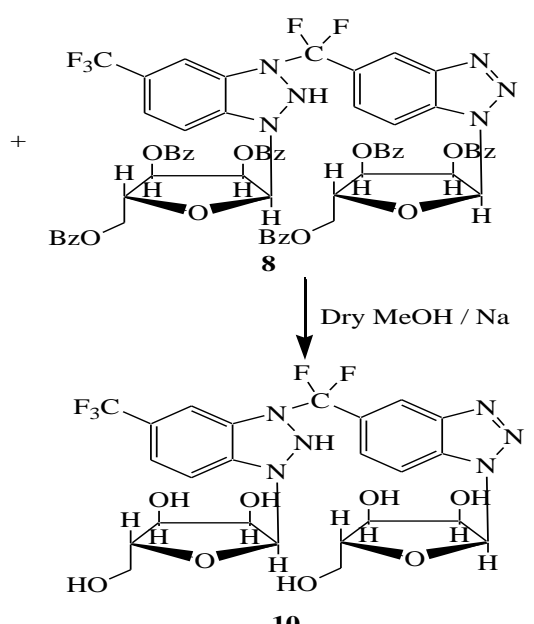

Scheme (2): Synthesis of 3-Benzotriazole-5-(yl)-difluoro-methyl-5-tri-fluoromethyl

benzotriazole Nucleosides

\section{Experimental}

The method for reduction of aromatic nitro compounds employing NaBH4/ Raney nickel system or Raney nickel only is simple, inexpensive, easily scaled-up and applicable for large scale preparation of different heterocyclic aryl amines (Chang et al, 1970; Mi et al, 2008; Mi et al, 2007 and Wang \& Zhou, 2011).

\section{3,4-Diaminobenzotrifluoride (2)}

A mixture of $4.46 \mathrm{~g}$. (0.0216 mole) of 4-Amino-3-nitrobenzotrifluoride (1), $50 \mathrm{ml}$. of absolute ethanol, and $1 \mathrm{~g}$. of Raney nickel and $5 \mathrm{ml}$ of hydrazine hydrate was added. the temperature is rapidly raised to $60-70^{\circ}$, Owing to the strong exothermic reaction. The reaction mixture was reflexed at $100-120^{\circ}$ for $3 \mathrm{~h}$. After the reaction mixture has cooled, the catalyst is separated from the reaction mixture by filtration through a Büchner funnel. The alcohol and water are removed by distillation, and the product was purified by flash column chromatography (silica gel $100 \mathrm{~g}$, chloroform /ethyl acetate 90: 10) to give $3.3 \mathrm{~g}$ (Ayyangar et al, 1984; Dauben et al, 1963 and Allen \& James, 1955).

Yield (87\%), m.p. 56 oC brown; IR (KBr) v cm-1: 3400 (NH2).1HNMR (600MHz); (CD3OD): 4.85 (s, 4H, $\mathrm{NH}) ; 6.68(\mathrm{~d}, 1 \mathrm{H}, \mathrm{J}=8.4 \mathrm{~Hz}, \mathrm{H}-6) ; 6.81(\mathrm{~d}, 1 \mathrm{H}, \mathrm{J}=8.4 \mathrm{~Hz}, \mathrm{H}-7) ; 6.90(\mathrm{~s}, 1 \mathrm{H}, \mathrm{H}-4) .13 \mathrm{CNMR}(600 \mathrm{MHz})$ CD3OD: $\quad 140.06,135.67,129.27,125.70,117.32,115.79,113.50$. Anal. Calcd. for C7H7F3N2; M.wt: 176.14; C,47.73; H,4.01; F,23.36; N, 15.90; (\%); Found: C, 47.13; H, 3.99; F, 23.04; N,15.10 (\%).

3-Benzotriazole-5-(yl)-difluoro-methyl-5-tri-fluoromethyl benzotriazole (3)

To a solution of (2) (3 g, $0.017 \mathrm{mmol})$ in $(1 \mathrm{ml})$ glacial acetic acid and $\mathrm{H} 2 \mathrm{O}(10 \mathrm{ml})$ added $2.3 \mathrm{~g} \mathrm{NaNO} 2 \mathrm{in} \mathrm{H} 2 \mathrm{O}$ 
$(5 \mathrm{ml})$ at $0 \mathrm{oC}$ in ice bath. After stirring for $10 \mathrm{~m}$, the color was changed to brown. A precipitate formed in an icewater collected by vacuum filtration and it washed three times with ice-water. It was purified by flash column chromatography (silica gel $100 \mathrm{~g}$, chloroform /ethyl acetate 90: 10) to give $3.3 \mathrm{~g}(54.62 \%)$ (Wang \& Zhou, 2011).

Yield (54.62\%), m.p. 127oC dark brown; IR (KBr) $v$ cm-1: $1630(\mathrm{C}=\mathrm{N})$; 1HNMR (600MHz); (CD3OD): 1.90 $(\mathrm{s}, 1 \mathrm{H}, \mathrm{NH}) ; 1.87$ (s, 1H, NH); 7.61 ( d, 1H, J = 8.5 H-6); $7.76\left(\mathrm{~d}, 1 \mathrm{H}, \mathrm{J}=8.5 \mathrm{~Hz}, \mathrm{H}-6^{\prime}\right) ; 7.90$ ( d, 1H, J = $8.5 \mathrm{~Hz}$, H-7); $8.03(\mathrm{~d}, 1 \mathrm{H}, \mathrm{J}=8.5, \mathrm{H}-7) ; 8.17\left(\mathrm{~s}, 1 \mathrm{H}, \mathrm{H}-7^{\prime}\right) ; 8.31(\mathrm{~s}, 1 \mathrm{H}, \mathrm{H}-4) .13 \mathrm{CNMR}(600 \mathrm{MHz})$ CD3OD: 141.14 (CF2), 140.22, 128.89, 128.68, 128.46, 128.25, 126.62, 124.82, 123.75, 123.53, 123.02, 116.21, (CF3), 115.32. Anal. Calcd. for C14H7F5N6; M.wt: 354.24; C, 47.47; H,1.99; F,26.82; N, 23.72; (\%); Found: C, 46.98; H, $1.54 ; \mathrm{F}, 26.25 ; \mathrm{N}, 23.10(\%) . \mathrm{M}+1=355.2(3)$

Synthesis of $\alpha \quad \beta$ and $(2,3,5$-Tri- $O$-benz-oyl- $\beta$-Dribofuranosyl) 3-Benzotriazole-5-(yl)-difluo-romethyl-5-trifluoromethyl benzotriazole (7) and (8).

Ribosylation 3-Benzotriazole-5-(yl)- difluorome-thyl-5-trifluoromethyl benzotriazole (3). Synthe-sis of $\alpha$ and $\beta$-1-(2,3,5-tri-O-benzoyl- -D-ribo-furanosyl)-3-Benzotriazole-5-(yl)-difluorometyl-5-trifluoro-methyl benzotriazole (7) and (8).

General Procedure.

A mixture of 3-Benzotriazole-5-(yl)-difluorome-thyl-5-trifluoromethyl benzotriazole (3) (0.02 mol) and hexamethyl disilazane $(20 \mathrm{ml})$ was heated under reflux for $24 \mathrm{~h}$ with a catalytic amount of ammonium sulfate $(0.01 \mathrm{~g})$. After that, the clear solution was cooled and evaporated till dryness to give the silyated derivative (5), which directly was dissolved in $20 \mathrm{ml}$ of dry 1,2-dichloroethane and then 1-O-acetyl-2,3,5-tri-O-benzoyl-Dribofuranose (6) $(5.05 \mathrm{~g}, 0.01 \mathrm{~mol}$ ) was added. The mixture was added dropwise onto a mixture of (10 ml trimethylsilyl trifluoromethane sulfonate (TMSOTf) in dry 1,2-dichloroethane $(50 \mathrm{ml}))$. All mixture was stirred at room temperature for $24 \mathrm{~h}$, and then washed with a saturated solution of aqueous sodium bicarbonate $(3 \times 50 \mathrm{ml})$, washed with water $(3 \times 50 \mathrm{ml})$, and dried over anhydrous sodium sulfate. The solvent was removed in vacuum gave an anomeric mixture of $\alpha$ and $\beta$-1-(2,3,5-tri-O-benzoyl- $\beta$-D-ribofuranosyl)-3-Benzotriazole-5-(yl)-difluoro-methyl-5-trifluoro-methyl benzotriazole (7) and (8). This mixture has been separted into the two components by on silica gel with chloroform: acetone $(9: 1)$ as eluent to afford a white crystal pure -anomeric(7) and -anomeric (8) respecttively.

\section{$\beta$-1-(2,3,5-Tri- $O$-benzoyl- $\beta$-D-ribofuranosyl)-3-Benzotriazole-5-(yl)-difluo-romethyl-5-trifluoro-methyl} benzotriazole (7)

Yield (38.85\%), w. $3.02 \mathrm{~g}$, m.p. $115^{\circ} \mathrm{C}$ white; $v\left(\mathrm{~cm}^{-1}\right)(\mathrm{KBr}) 1740(\mathrm{C}=\mathrm{O}), 1670(\mathrm{C}=\mathrm{N}) ;{ }^{1} \mathrm{HNMR}(850 \mathrm{MHz})$; $\left(\mathrm{CDCl}_{3}\right): \delta 1.57(\mathrm{~s}, 1 \mathrm{H}, \mathrm{NH}), 3.49$ (m, 1H, H-5'); 3.46 (m, 1H, H-5"); 4.58-4.55 (dd, 1H, H-4'); 4.81-8.79 (dd, 1H, H-4"); 4.89-4.47(m, 1H, H-3'); 5.00-4.96 (m, 1H, H-3"); 6.31-6368 (t, 1H, H-2', J = 5.8 Hz); 6.61-6.60 (t, 1H, H-2", $J=5.8 \mathrm{~Hz}) ; 6.67\left(\mathrm{~d}, 1 \mathrm{H}, \mathrm{H}-1^{\prime}, J_{1^{\prime}, 2^{2}}=7.5 \mathrm{~Hz}\right) ; 6.73\left(\mathrm{~d}, 1 \mathrm{H}, \mathrm{H}-1^{\prime \prime}, J_{1^{\prime \prime}, 2^{\prime \prime}}=7.5 \mathrm{~Hz}\right) ; 8.30-7.38(\mathrm{~m}, 37 \mathrm{H}, \mathrm{Ar}-\mathrm{H})$.

${ }^{13} \mathrm{CNMR}(850 \mathrm{MHz})\left(\mathrm{CDCl}_{3}\right) \delta 166.03,165.97,165.22,165.19,165.17,164.41(6 \mathrm{C}=\mathrm{O}), 145.47$

$\left(\mathrm{CF}_{2}\right), 133.96,133.77,133.36,133.29,132.16,129.92,129.86,129.68,129.62,129.07,129.02$,

$128.65,128.58,128.48,128.43,127.34,127.19,124.92,124.50,124.38,123.23,123.10,121.36$,

118.51, $118.49\left(\mathrm{CF}_{3}\right), 110.95,108.12,108.10$,(Ar.C's), 89.23, 89.02, 81.32, 81.24, 74.70,74.40,71.62, 71.40, 63.3 9, 63.07 (sugar carbons),. Anal. Calcd. for $\mathrm{C}_{66} \mathrm{H}_{49} \mathrm{~F}_{5} \mathrm{~N}_{6} \mathrm{O}_{14} ;$ M.wt: 1245.15; C,63.67; H,3.97; F,7.63; N, 6.75; (\%); Found: C, 63.24; H, 3.01; F,7.52; N,5.31 (\%).

\section{$\alpha$-1-(2,3,5-Tri- $O$-benzoyl- $\beta$-D-ribofuranosyl)-3-Benzotriazole-5-(yl)-difluoromethyl-5-trifluoro-methyl} benzotriazole (8)

Yield (20.45\%), w. $1.59 \mathrm{~g}$, m.p. $98^{\circ} \mathrm{C}$ yellow; $v\left(\mathrm{~cm}^{-1}\right)(\mathrm{KBr}) 1740(\mathrm{C}=\mathrm{O}), 1670(\mathrm{C}=\mathrm{N}) ;{ }^{1} \mathrm{HNMR}(850 \mathrm{MHz})$; $\left(\mathrm{CDCl}_{3}\right): \delta 2.04$ (s, 1H, NH); 4.59-4.55 (m, 1H, H-5'); 4.80(m, 1H, H-5"); 4.81(t, 1H, H-4'); 4.89 (t, 1H, H-4"); $4.87(\mathrm{~d}, 1 \mathrm{H}, \mathrm{H}-3$ ', $J=4.5 \mathrm{~Hz}) ; 5.00-4.97$ (d, 1H, H-3", J=4.5 Hz); 6.31 (d, 1H, H-2', J=5.95 Hz); 6.62 (d, 1H, H-2", $J=5.95 \quad \mathrm{~Hz}) ; \quad 6.74 \quad\left(\mathrm{~d}, \quad 1 \mathrm{H}, \quad \mathrm{H}-1^{\prime}, \quad J_{1^{\prime}, 2^{\prime}} \quad=3.4 \quad \mathrm{~Hz}\right) ; \quad 6.67 \quad\left(\mathrm{~d}, \quad 1 \mathrm{H}, \quad \mathrm{H}-1^{\prime \prime}, \quad J_{1^{\prime \prime}, 2^{\prime \prime}}=3.4 \quad \mathrm{~Hz}\right)$; 8.29-7.26 (m, 37H, Ar-H). ${ }^{13} \mathrm{CNMR}(850 \mathrm{MHz})\left(\mathrm{CDCl}_{3}\right): 166.02,165.96,165.22,165.18,161.03,157.41(6 \mathrm{CO})$, $145.46\left(\mathrm{CF}_{2}\right), 133.95,133.75,133.35,133.28,132.17,130.71,130.55,130.40,130.25,129.92,129.86,129.62$, 129.08, 129.02, 128.65, 128.57, 128.51, 128.48, 128.43, 124.91, 124.51, 124.38, 123.23, 123.11, 121.38, 121.35, 118.49, $118.48\left(\mathrm{CF}_{3}\right), 110.98,108.12$, 108.10 (Ar. C's), 89.24, 89.02, 81.31, 81.23, 74.71, 74.59, 71.63, 71.40, 63.40, 63.07(sugar carbons). Anal. Calcd. for $\mathrm{C}_{66} \mathrm{H}_{49} \mathrm{~F}_{5} \mathrm{~N}_{6} \mathrm{O}_{14}$; M.wt: 1245.15; C,63.67; H,3.97; F,7.63; N, 6.75; (\%); Found: C, 63.08; H, 3.29; F,7.12; N,5.10 (\%). 


\section{Synthesis of nucleosides free}

Deprotection of $\quad \beta-\quad$ and $\quad \alpha$-1-(2,3,5-trihydroxy- $\beta$-D-ribofuranosyl)- $\quad 3$-Benzotriazole-5-(yl)difluor-omethyl-5-trifluoromethyl benzotriazole (9) and (10) respectively.

\section{General Procedure}

A mixture of each protected nucleoside $\beta(7), \alpha(8)$ (0.001 mol for each), dry absolute methanol (20 ml) and sodium metal $(0.055 \mathrm{~g}, 0.001 \mathrm{~mol})$ was stirred at room temperature for $48 \mathrm{~h}$. The solvent was evaporated under vacuum to give a colorless solid, which was dissolved in hot water and neutralized with acetic acid. The precipitate compound was chromate-graphic on silica gel with chloroform: ethyl acetate (9:1) as eluent to afford colorless and white crystals of the corresponding nucleosides $\beta(\mathbf{9})$ and $\alpha(\mathbf{1 0})$ respectively.

\section{$\beta$-1-(2,3,5-Trihydroxy- $\beta$-D-ribofuranosyl)-3-Benztriazole-5-(yl)-difluoro-methyl-5-trifluorometh-yl benztriazole (9)}

Yield (87\%), m.p. $<300^{\circ} \mathrm{C}$ white; $\left(\mathrm{H}_{2} \mathrm{O} / \mathrm{EtOH}, 1: 1\right) ; v\left(\mathrm{~cm}^{-1}\right)(\mathrm{KBr}) 3400(\mathrm{OH}) ;{ }^{1} \mathrm{HNMR}(850 \mathrm{MHz}) ;\left(\mathrm{CD}_{3} \mathrm{OH}\right)$ : $\delta 1.88$ (s, IH, NH); 3.67 (d, 2H, H-5' ); 3.68 (d, 68, 2H, H-5" ); 3.70 (d, 1H, H-3'); 3.78 (d, 1H, H-3"); 3.79 (t, 1H, H-4'); 3.80 (d, 1H, H-4"); 4.22(m, 1H, H-2'); 4.19 (m, 1H, H-2"); 4.47 (t, 1H, OH-5'); 4.91 (t, 1H,OH-3');4.93 (d, $\left.1 \mathrm{H}, \mathrm{OH}-2^{\prime}, \mathrm{J}=5.5 \mathrm{~Hz}\right) ; 6.41\left(\mathrm{~d}, 1 \mathrm{H}, \mathrm{H}-1^{\prime}, J_{1^{\prime}, 2^{\prime}}=7.5 \mathrm{~Hz}\right) ; 6.46\left(\mathrm{~d}, 1 \mathrm{H}, \mathrm{H}-1^{\prime \prime}, J_{1^{\prime \prime}, 2^{\prime \prime}}=7.5 \mathrm{~Hz}\right) ; 8.30(\mathrm{~s}, 1 \mathrm{H}) .{ }^{13} \mathrm{CNMR}$ $(850 \mathrm{MHz})\left(\mathrm{CD}_{3} \mathrm{OH}\right): \delta 180.41,175.58,148.51\left(\mathrm{CF}_{2}\right), 146.42,139.07,135.78,133.47,131.21,130.23,128.68$, 128.24, 128.09, 125.43, 122.43, 121.58 (Ar C's), 118.51( $\left.\mathrm{CF}_{3}\right), 113.85,93.22,92.94,87.66,87.54,75.39,75.09$, 72.28, 72.22, 63.17, 63.06 (sugar carbons), 24.19. Anal. Calcd. for $\mathrm{C}_{24} \mathrm{H}_{25} \mathrm{~F}_{5} \mathrm{~N}_{6} \mathrm{O}_{8}$; M.wt: 620.848; C,46.46; H,4.06; F, 15.31; N, 13.54; (\%); Found: C, 46.21; H, 3.89; F,15.12; N,12.95 (\%).

\section{$\alpha$-1-(2,3,5-Trihydroxy- $\beta$-D-ribofur-anosyl)-3-Benzotriazole-5-(yl)-difluoro-methyl-5-trifluoro-methyl benzotriazole (10)}

Yield (65\%), m.p. $<300^{\circ} \mathrm{C}$ white; $\left(\mathrm{H}_{2} \mathrm{O} / \mathrm{EtOH}, 1: 1\right) ; v\left(\mathrm{~cm}^{-1}\right)(\mathrm{KBr}) 3400(\mathrm{OH}) ;{ }^{1} \mathrm{HNMR}(850 \mathrm{MHz}) ;\left(\mathrm{CD}_{3} \mathrm{OH}\right)$ : $\delta 1.88(\mathrm{~s}, \mathrm{IH}, \mathrm{NH}) ; 3.30-3.29\left(\mathrm{~m}, 1 \mathrm{H}-5^{\prime}\right) ; 3.68\left(\mathrm{~d}, 1 \mathrm{H}, \mathrm{J}=5.1 \mathrm{~Hz}, \mathrm{H}-5^{\prime \prime}\right) ; 3.69\left(\mathrm{t}, 1 \mathrm{H}, \mathrm{H}-4^{\prime}\right) ; 3.71(\mathrm{~d}, 1 \mathrm{H}, \mathrm{J}=4.25$ $\left.\mathrm{Hz}, \mathrm{H}-4^{\prime \prime}\right) ; 3.78\left(\mathrm{~d}, 1 \mathrm{H}, \mathrm{J}=3.4 \mathrm{~Hz}, \mathrm{H}-3^{\prime}\right) ; 3.79\left(\mathrm{t}, 1 \mathrm{H}, \mathrm{H}-3 \mathrm{3}^{\prime}\right) ; 3.80\left(\mathrm{~d}, \mathrm{~J}=3.4 \mathrm{~Hz}, 1 \mathrm{H}, \mathrm{H}-2^{\prime}\right) ; 4.23(\mathrm{~m}, 1 \mathrm{H}$, H-2");4.49 (t, 1H, OH-5'); 4.93 (t, 1H, OH-3'); 4.94 (d, 1H, J= 5.1 Hz, OH-2'); 6.43 (d, 1H, J= 4.25 Hz, H-1'); 6.47 (d, 1H, J= 4.25 Hz, H-1"); 8.55-7.31 (m, 6H, Ar-H).

${ }^{13} \mathrm{CNMR}(850 \mathrm{MHz})\left(\mathrm{CD}_{3} \mathrm{OH}\right): \delta 175.62\left(\mathrm{CF}_{2}\right), 148.45,146.36,139.05,135.75,133.44,131.21,130.230,128.67$, 128.24, 125.41, 122.29, 121.57, 121.55, $118.48\left(\mathrm{CF}_{3}\right), 113.86,111.25$ (Ar. C's,), 93.22, 92.96, 87.67, 87.54, 75.40, 72.26, 72.19, 63.17, 63.06 (sugar carbons), 24.23. Anal. Calcd. for $\mathrm{C}_{24} \mathrm{H}_{25} \mathrm{~F}_{5} \mathrm{~N}_{6} \mathrm{O}_{8}$; M.wt: 620.848; C,46.46; H,4.06; F,15.31; N, 13.54; (\%); Found: C, 46.21; H, 3.89; F,15.12; N,12.95 (\%).

\section{Results and Discussion}

Reduction of nitro group of compound, 4-Amino-3-nitrobenzotrifluoride (1) was used Raney Nickle and hydrazine in ethanol was prepared, 1,2-Diamino-4-benzotrifluoride (2) as reported in the literature (Wang \& Zhou, 2011). Compound (2) was stirred with water glacial acetic acid in ice bath then solution $\mathrm{NaNO}_{2}$ was dropped to $10 \mathrm{~min}$ gave of the dimer 3-Benzotriazole-5-(yl)-difluoromethyl-5-trifluor-omethyl benzotriazole in yield of $54.62 \%$ comp-ound (3) and some stsrting material, although the product dimerized as unexpected (Scheme 1). The structures of the latter products (2), and (3) were established and confirmed on the bases of their elemental analyses and spectral data. Thus, their ${ }^{1}$ H NMR spectra of compound (2) showed two a doublet signals at $\delta 6.68,6.81$ assigned to the aromatic protons of H-6 and H-7 and a singlet signal at 6.90 of H-4 and a singlet signal at $\delta 4.85$ of $\mathrm{NH}_{2}{ }^{1}{ }^{1} \mathrm{H}$ NMR spectra of compound (3) showed four doublet signals at $\delta 7.61,7.76,7.90$ and 8.03 with spin-spin coupling constant $\left(\mathrm{J}_{\mathrm{H}-6}\right),\left(\mathrm{J}_{\mathrm{H}-6}\right),\left(\mathrm{J}_{\mathrm{H}-7}\right)$ and $\left(\mathrm{J}_{\mathrm{H}-7^{\prime}}\right)$ equal to $8.5 \mathrm{~Hz}$, assigned to the aromatic protons of H-6, H-6', H-7 and H-7', and two singlet signals at 8.17 and 8.31 of H-4 and H-4'.

The ${ }^{13} \mathrm{C}$ NMR of compound (2) revealed the seven signals at $\delta 140.06,135.67,129.27,125.70,117.32,115.79$, 113.50. The fourteen signals at $\delta 141.14\left(\mathrm{CF}_{2}\right), 140.22,128.89,128.68,128.46,128.25,126.62,124.82,123.75$, 123.53, 123.02, 116.21 of compound (3). HMBC (see Fig(1)). 2D NMR Experiments to characterize dimers of benzotriazole and for studies on the conformation of 3-Benzotriazole-5-(yl)-difluoromethyl-5-tri-fluoromethyl benzotriazole. The spectrum of sucrose at $850 \mathrm{MHz}$ is shown below. The peak outlined in green shows the two bond correlation between the C-5 carbon and the H- 6 proton. The peak outlined in red correlates the $\mathrm{CF}_{2}$ carbon and H-7 proton separated by 4 bonds. The peak outlined in bule correlates the C- 5 carbon and H-4 proton separated by 3 bonds. Note also that the C-7 carbon correlates with the H-7 proton across bond. (Diana et al, 2007; Katritzky et al, 1998; Katritzky et al, 2003 and Shi et al, 2011).

IR spectra of compound (2) showed absorptions around $3400 \mathrm{~cm}^{-1}$ for $\left(\mathrm{NH}_{2}\right)$. While the $\left(\mathrm{NH}_{2}\right)$ group 
disappeared of compound (3), showed absorptions $1630 \mathrm{~cm}^{-1}$ for $(\mathrm{C}=\mathrm{N})$. Mass spectra of compound (3) $\mathrm{M}+=$ 355.2 .
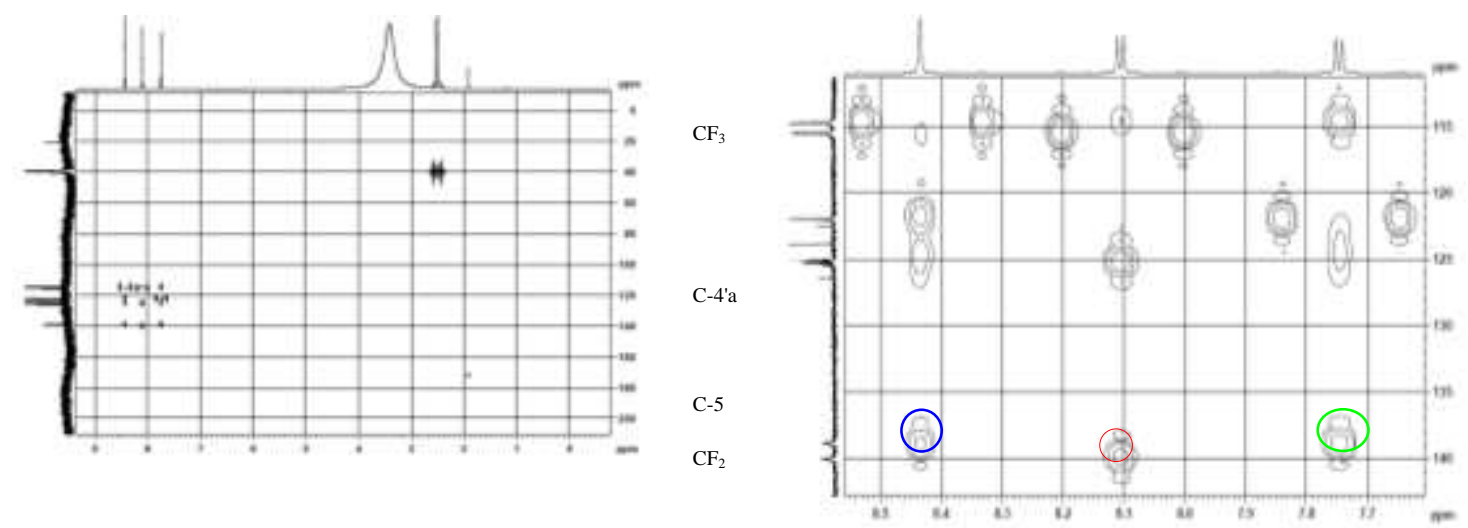

Fig (1). HMBC (Heteronuclear Multiple Bond Correlation) of compound (3)<smiles>CC(C)(C)c1ccc2c(c1)N=CC2</smiles>

3-Benzotriazole-5-(yl)-difluoro-methyl-5-trifluoromethyl benzotriazole (3)

Ribosylation of (3) was achieved by refluxing in hexamethyldisilazane (HMDS) to give the silylated derivatives (5) The latter was stirred with 1- $O$-acetyl-2,3,5-O-benzoyl- $\beta$-D-ribofura-nose (6) in the presence of dry 1,2-dichloroethane as solvent using trimethylsilyl trifluoromethane-sulfonate (TMSOTf) as a catalyst for $24 \mathrm{~h}$ (followed by TLC), following the silylation method according to to give the corresponding $\beta$-anomeric (7) and $\alpha$-anomeric (8) protected $N$-nucleoside derivatives, respectively, in good yields (Vorbruggen et al, 1981). The mixture was separated by used column chromatography.

Debenzoylation of (7) and (8) were performed by using methanolic sodium methoxide solution following Zemplen et al.'s method (Zemplen et al, 1939) to afford the free nucleosides (9) and (10), respectively (Scheme 2).

The chemical structures of nucleoside deriveatives (2)-(10) were established and confirmed on the basis of their elemental analyses and spectral data (IR, ${ }^{1} \mathrm{H}$ and ${ }^{13} \mathrm{C}$ NMR) (see the Experimental section). ${ }^{1} \mathrm{H}$ NMR spectra of (7) and (8) showed in each case a doublet signals at $\delta 6.67,6.73$ for compound (7) and at $\delta 6.74,6.67$ for compound (8) assigned to the anomeric proton of the ribose moiety with spin-spin coupling constant $\left(\mathbf{J}_{1^{\prime}, 2^{\prime}}\right)$ and $\left(\mathrm{J}_{1^{\prime \prime}, 2^{\prime \prime}}\right)$ equal to $7.5 \mathrm{~Hz}$, which confirms the $\beta$-anomeric configuration. While confirms the $a$-anomeric configuration showed spin-spin coupling constant $\left(\mathrm{J}_{1^{\prime}, 2^{2}}\right)$ and $\left(\mathrm{J}_{1^{\prime \prime 2}, 2^{\prime \prime}}\right)$ equal to $3.4 \mathrm{~Hz}$, which confirms the $a$-anomeric configuration for compound (8) (Mosselhi, 1993; Mosselhi, 1999;Mosselhi \& Seliger, 2001; Mosselhi \& Break, 2011; Break et al, 2010; Metwally et al, 2010;Mosselhi \& Neidlein,, 2009; Breaket al, 2013 and Khalil, 2006). The ${ }^{1} \mathrm{H}$ NMR spectra of nucleosides free showed a doublet signals at $\delta 6.41,6.46$ for compound (9) spinspin coupling constant $\left(\mathrm{J}_{1^{\prime}, 2^{2}}\right)$ and $\left(\mathrm{J}_{1^{\prime \prime}, 2^{\prime \prime}}\right)$ equal to $7.5 \mathrm{~Hz} \beta$-anomeric configuration and at $\delta 6.43$, 6.47 for compound (10) assigned to spin-spin coupling constant $\left(J_{1^{\prime}, 2^{\prime}}\right)$ and $\left(J_{1^{\prime \prime}, 2^{\prime \prime}}\right)$ equal to $4.25 \mathrm{~Hz}$, which confirms the $a$-anomeric configuration.

The ${ }^{13} \mathrm{C}$ NMR of nucleoside products revealed the signals at $\delta 166.03,165.97,165.22,165.19,165.17$ and 164.41 are due to the six benzoyl carbonyl groups for compound (7), and 166.02, 165.96, 165.22, 165.18, 161.03 and 157.41 are six carbonyl groups for compound (8). The ten signals at $\delta 89.23,89.02,81.32,81.24,74.70,74.40,71.62,71.40,63.39$ and 63.07 for comp-ound (7), and The ten signals at $\delta 89.24,89.02,81.31,81.23,74.71,74.59,71.63,71.40,63.40$ and 63.07 for compound $(\mathbf{8})$ were assigned to C-1', C-1", C-2', C-2" , C-3' , C-3' ,C-4', C-4", C-5' and C-5" of the sugar moiety, respectively. The $\mathrm{CF}_{2}$ group showed at 145.47 and 145.46 of compound (7) and (8) respectively. The ${ }^{1} \mathrm{H}$ NMR of (7) and (8) showed the expected base moiety protons in addition to the sugar moiety protons (see the Experimental section). The IR spectrum of compounds (7) and (8) showed the stretching vibration frequencies of the benzoyl carbonyl $\mathrm{C}=\mathrm{O}$ groups at $1740 \mathrm{~cm}^{-1}$. IR spectra of compounds (9) and (10) showed absorptions around $3400 \mathrm{~cm}^{-1}$ for $(\mathrm{OH})$. 


\section{Conclusion}

Benzotriazoles are scientific importance in many biologically active compounds. So synthesis and characterization of 3-Benztriazole-5-yl difluoro-methyl-5-trifluoromethyl benztriazole (3). Ribosylation of compound (3) with 1- $O$-acetyl-2,3,5-tri- $O$-benzoyl- $\beta$-D-ribofuranose(6) afforded mixture $\beta$ - and $\alpha$ - anomeric of the benzoylated nucleoside derivatives (7) and (8), respectively.

Deprotection of the latter by using dry absolute methanol and sodium metal gave new free $\mathrm{N}$-nucleosides (9) and (10), respectively, in moderate yields. Nucleosides obtained have been identified by their spectral analysis.

\section{References}

Allen, C. F. H., \& James, V. A. (1942). 2-AMINO-p-CYMENE. Organic Syntheses, Coll., 3.

Ayyangar, N. R., Brahme, K. C., Kalkote, U. R., \& Srinivasan, K. V. (1984). Facile Transfer-Reduc-tion of Nitroarenes to N Arylhydroxylamines with Hydrazine in the Presence of Raney Nickel. Synthesis, (11), 938. http://dx.doi.org/10.1055/s-1984-31027

Break, L. M., Shmiss, N. A. M. M., \& Mosselhi, M. A. N. (2010). Synthesis of some news-nucleo-side derivatives of 2-thioxo and (2,4-Dithioxo)-5,6,7,8-Tetrahydrobenzo-Thieno[2,3-d]Pyrimi-din-4-(3H) Ones. Phosphorus, Sulfur and Silicon and the Related Elements, 185(8), 1615-1622. http://dx.doi.org/10.1080/10426500903147159

Chang, J. J., Wang, Y., Zhang, H. Z., Zhou, C. H., Geng, R. X., Ji, Q. G. (2011). Recent advances in researches of triazole-based supramolecular che-mistry and medicinal drugs. Chem. J. Chinese U., 32, 1970-1985(in Chinese).

Chun, M. W., Kim, J. H., Kim, M. J., Kim, B. R., \& Jeo-ng, L. S. (2005). Synthesis of homo-N-nucleoside with 1,2,4-triazole-3-carboxamide. Nucleosides Nuc-leotides Nucleic Acids., 24(5-7), 979-81. PMID:16248076. http://dx.doi.org/10.1081/NCN-200059368

Dauben, Jr. H. J., Ringold, H. J., Wade, R. H., Pearson, D. L., \& Anderson, Jr. A. G. (1963). Cycloheptanone. Org. Synth.; Coll., 4, 221.

Dawood, K. M., Abdel-Gawad, H., Rageb, E. A., Ellithey, M., \& Mohamed, H. A. (2006). Synthesis, anticonvulsant, and anti-inflammatory evaluation of some new benzotriazole and benzofuran-based heterocycles. Bioorg. Med. Chem., 14, 3672. http://dx.doi.org/10.1016/j.bmc.2006.01.033

Diana, C. G. A., P., Clementina, M. M. S., \& Artur M. S. S. (2007). Advanced NMR techniques for structural characterization of heter-ocyclic structures. Recent Research Develop-ments in Heterocyclic Chemistry, 397-475 ISBN: 81-308-0169-8

Handratta, V. D., Vasaitis, T. S., Njar, V. C. O., Gediya, L. K., Kataria, R., Chopra, P., Newman, D., Farquhar, R., Guo, Z., Qiu, Y., \& Brodie, A. M. H. (2005). Novel C-17-heteroaryl steroi-dal CYP17 inhibitors/antiandrogens: synthesis, in vitro biological activity, pharmacokinetics, and antitumor activity in the LAPC4 human prostate cancer xenograft model. J. Med. Chem., 48, 2972.

Haukur, K., Kurt, N., Anthony, C. O’S, Fritzm, S., Tammom W., \& Yasuchika, Y. (1994). A Novel Synthesis of $\begin{array}{llll}\text { Sulfamoyl Nucleosides. } & \text { Terrahedron, }\end{array}$ http://dx.doi.org/10.1016/S0040-4020(01)81336-3

Katritzky, A. R., Akhmedov, N. G., Ghivi-riga, I., Denisko, O. V., \& Steel, P. J. (2003). J. Phys. Org. Chem., 16, 158. http://dx.doi.org/10.1002/poc.588

Katritzky, A. R., Yang, B., \& Pleynet, D. P. M. (1998). Novel Heterocyclic Analogs of Trityl Radicals: Synthesis and Dimerization of Diarylmethyl-1H-1,2,4-Triazoles and Diaryl-methyl-2H-Phenanthro[9,10-d]-1,2,3-Triazoles. J. $\quad$ Org. $\quad$ Chem., $\quad 63, \quad 9992$. http://dx.doi.org/10.1021/jo980618f

Khabnadideh, S., Rezaei, Z., Pakshir, K., Zomorodian, K., \& Ghafari. N. (2012). Synthesis and an-tifungal activity of benzimidazole, benzo-triazole and aminothiazole derivatives. Res Pharm Sci. Apr., 7(2), 65-72.

Khalil, N. S. A. M. (2006). Efficient synthesis, structure, and antimocrobial activity of some novel N- and S- -D-glucosides of 5-pyridin- 3-yl-1,2,4-triazoles. Carbohydrate Res., 341, 2187-2199. http://dx.doi.org/10.1016/j.carres.2006.06.007

Konstantinova, I. D., Chudinov, M. V., Fateev, I. V., Matveev, A. V., Zhurilo, N. I., Shvets, V. I., \& Miroshnikov, A. I. (2013). Nucleosides of 1,2,4-triazole: potentialities and restrictions of chemo-enzymatic method for 
synthesis. Bioorg Khim., 39(1), 61-80.

Laila, M. B., Mosselhi, A. M., \& Nagi, M. E. (2013). Nucl-eosides 8 [18]: Ribosylation of Fused Quina-zolines-Synthesis of New [1,2,4]Triazolo [5,1-b] and [1,2,4]Triazino[3,2-b] quinazoline Nucleo-sides of Fluorescence Interest. Journal of Chemistry., 2013, Article ID 612756, 11.

Metwally, N. H., Abdalla, M. A., Mosselhi, M. A. N., \& El-Desoky, E. A. (2010). Synthesis and antimicrobial activity of some new N-glycosides of 2-thioxo-4-thiazolidinone derivatives. Carbo-hydrate Research, 345(9), 1135-1141. http://dx.doi.org/10.1016/j.carres.2010.04.011

Mi, J. L, Zhou, C. H., Bai, X. (2007). Advances in triazole antimicrobial agents. Chin. J. Antibiot., 32, 587-593(in Chinese).

Mi, J. L., Wu, J., \& Zhou, C. H. (2008). Progress in anti-tumor agents: triazoles. West China J. Pharm. Sci., 23, 84-86(in Chinese).

Mosselhi, M. A. N. (1999). Nucleosides 2: synth-esis and properties of 3,4-diaryl-4,5-dihydro-1-( $\beta$-D-ribofuranosyl)-1,2,4-triazole-5-thiones. Nucleosides and Nucleotides, 18(9), 2043-2049. http://dx.doi.org/10.1080/07328319908044863

Mosselhi, M. A. N., \& Break, L. M. (2011). NUCL-EOSIDES 7: synthesis, structure and biological activity of new 6-arylidenamino-2-thio- and 2-benzylthiopyrimidine N-Nucleosides. Nucleo-sides Nucleotides and Nucleic Acids, 30(9), 681-695. http://dx.doi.org/10.1080/15257770.2011.597628

Mosselhi, M. A. N., \& Neidlein, R. (2009). Nucle-osides 515: synthesis of novel 1,2,4-triazolo[3,4-c]-1,2,4-triazole nucleosides. Nucle-osides, Nuc-leotides and Nucleic Acids, 28(11-12), 1095-1103. http://dx.doi.org/10.1080/15257770903368377

Mosselhi, M. A. N., \& Neidlein, R. (2009). Nucle-osides 515: synthesis of novel 1,2,4-triazolo[3,4-c]-1,2,4-triazole nucleosides. Nucleosides, Nucl-eotides and Nucleic Acids, 28(11-12), 1095-1103. http://dx.doi.org/10.1080/15257770903368377

Mosselhi, M. A. N., \& Nucleosides, I. (1993). Ribosyl-ation of 8-substituted theophylline derivatives. Nucleosides and Nucleotides, 12(5), 431-439. http://dx.doi.org/10.1080/07328319308021213

Mosselhi, M. A. N., \& Seliger, H. (2001). Nucleo-sides 31: synthesis of novel 1,3,4-oxadiazole nucleosides. Journal of Chemical Research S, no. 9, 359-361. http://dx.doi.org/10.3184/030823401103170278

Sanna, P., Carta, A., Gherardini, L., \& Niko-okar, M. E. R. (2002).Synthesis and antimycobacterial activity of 3-aryl-, 3-cyclohexyl- and 3-heteraryl-substituted-2-(1H(2H)-benzotriazol-1(2)-yl)prop-2-enenitril-es, prop-2-enamides and propenoic acids. II. Il Farmaco, 57, 79.

Shi, Y., Zhou, C. H., Zhou, X. D., Geng, R. X., Ji, Q. G. (2011). Synthesis and antimicrobial evalu-ation of coumarin-based benzotriazoles and their synergistic effects with Chlromycin and Flucon-azole. Acta Pharm. Sinica, 46, 798-810(in Chinese).

Vorbruggen, H., Krolikiewicz, K., \& Bennua, B. (1981). Chem. Ber., 114, 1234. http://dx.doi.org/10.1002/cber.19811140404

Wang, Y., Zhou, C. H. (2011). Recent advances in the researches of triazole compounds as medici-nal drugs. Scientia Sinica Chemica, 41, 1429-1456(in Chinese).

Xia, Y., Qu, F., \& Peng, L. Triazole Nucle-oside Derivatives Bearing Aryl Functionalities on the Nucleobases. Antiviral and Anticancer Activity, (16), 806-821,

Xia, Y., Qu, F., Peng, L. (2010).Triazole nucleoside derivatives bearing aryl functionalities on the nucleobases show antiviral and anticancer activity. Mini Rev Med Chem., 10(9), 806-821. http://dx.doi.org/10.2174/138955710791608316

Zemplen, G., Gerecs, A., \& Hadacsy, I. (1939). Ber. Dtsch. Chem. Ges., 69, 1827

Zhou, C. H., \& Wang, Y. (2012). Recent Researches in Triazole Compounds as Medicinal Drugs. Current Medicinal Chemistry, 19, 239-280. http://dx.doi.org/10.2174/092986712803414213

\section{Copyrights}

Copyright for this article is retained by the author(s), with first publication rights granted to the journal.

This is an open-access article distributed under the terms and conditions of the Creative Commons Attribution license (http://creativecommons.org/licenses/by/3.0/). 